\title{
Can a woman with sexual dysfunction take sildenafil citrate?
}

\author{
Original \\ Abdalla Kandil, Abdulla Esawy \\ Article \\ Department of Dermatology and Venereology, Faculty of Medicine, Zagazig University, \\ Zagazig, Egypt
}

\begin{abstract}
Background: Sexual dysfunction refers to a problem that occurs during the sexual response cycle that prevents the individual from experiencing satisfaction from sexual activity. The assessment of sexual function in women is frequently confounded by many factors, including depressed mood and other comorbid medical and psychiatric disorders. Sildenafil is selective type 5 phosphodiesterase (PDE5) inhibitors, taken orally and effective for men with erectile dysfunction. Previous studies suggested that sildenafil, which acts by inhibiting cyclic GMP specific PDE5 may improve the sexual health of women affected by sexual difficulties such as arousal disorders and may indirectly improve other aspects of sexual life. Sildenafil was effective and well-tolerated in postmenopausal women with sexual arousal disorder without concomitant hypoactive sexual desire disorder or contributory emotional relationship or historical abuse issues.

Objective: This study aims to evaluate the effect of sildenafil citrate on female sexual dysfunction.

Patients and Methods: The study was conducted in Dermatology, Venereology, and Andrology Department, Faculty of Medicine, Zagazig University Hospitals during the period from April 2017 to August 2018. Fifty-two married female patients were included in this study. Patients were divided into two groups. Group 1 contains twenty-six patients took 50mg sildenafil on-demand and group 2 contains twenty-six patients took a placebo.

Results: There were no significant differences between the studied groups regarding the demographic data and FSFI. There were significant differences between pre and post-treatment of sexual dysfunction regarding group I. There were no significant differences in post-treatment results between the two studied groups as regard sexual dysfunction except in orgasm.

Conclusion: Sildenafil citrate may be effective in women who could not achieve orgasm.
\end{abstract}

Key Words: Female, sexual dysfunction, sildenafil.

Received: 21 July 2019, Accepted: 28 October 2019

Corresponding Author: Abdulla Esawy, MD, Lecturer of Dermatology, Venereology, and Andrology, Faculty of Medicine, Zagazig University, Egypt, Tel.: +2 01143156920, E-mail: abdesawy@hotmail.com

ISSN: 2090-6048, June 2019 Vol. 9, No. 2

\section{INTRODUCTION}

Female Sexual Dysfunction (FSD) is a disturbance or dysfunction in the process of desire, arousal or orgasm, which can be a symptom of a biological condition, a psychological problem, or an interpersonal issue or a combination of these factors ${ }^{[1]}$.

Female Sexual Dysfunction is a multi-causal and multi-dimensional medical problem that adversely affects physical health and emotional wellbeing. Also, impaired sexual function can have damaging effects on the selfesteem, sense of wholeness and interpersonal relationships of women. It is often emotionally distressing and might lead to familial discord and divorce, and reproduction is affected $^{[2]}$.

Selective type 5 phosphodiesterase (PDE5) inhibitors as sildenafil, which acts by inhibiting cyclic GMP specific PDE5 effective for men with erectile dysfunction may improve the sexual health of women affected by sexual difficulties such as arousal disorders and may indirectly improve other aspects of sexual life ${ }^{[3]}$.

Sildenafil was effective and well-tolerated in postmenopausal women with sexual arousal disorder without concomitant hypoactive sexual desire disorder or contributory emotional relationship or historical abuse issues $^{[4]}$.

Patients groups: The study was conducted in the Department of Dermatology, Venereology, and Andrology, Faculty of Medicine, Zagazig University Hospitals during the period from April 2017 to August 2018. Fifty-two married female patients were included in this study. Consents were taken from the patients. Patients were divided into two groups. Group 1 includes twenty-six patients took $50 \mathrm{mg}$ sildenafil on-demand and group 2 contains twenty-six patients took a placebo.

The Institutional Review Board (IRB) provided ethical approval for this study (Institutional Review Board 
$\mathrm{N}^{\circ} 1995$ ) for Faculty of Medicine, Zagazig University, and Zagazig, Egypt onMarch 3, 2017.

Inclusion criteria: Married female patients complaining of sexual dysfunction for more than 6 months and not on drug therapy for the treatment of FSD.

Exclusion criteria: Patients with sexual dysfunction caused by localized disorders, patients with retinal problem, patients with chronic debilitating diseases or hormonal disturbance, patients cannot be treated with PDEs inhibitors type 5 (sildenafil) as: Major hematological, renal or hepatic abnormalities, patients with major psychological disorders including major depression or psychosis, a history of stroke or myocardial infarction or any significant cardiovascular disease within the last 6 months, or concomitant treatment with nitrates.

\section{PATIENTS AND METHODS}

All patients in the 2 groups were subjected to Complete history taking: age, education, occupation, residence, age of marriage, special habits, history of medical diseases, surgical history and sexual history in the previous 6 months General and physical examination: pulse, blood pressure, routine laboratory investigations including complete blood count, liver function tests, renal function tests, blood sugar, and lipid profiles. Fundus examination. Evaluation questionnaire used included 25 items designed by the investigators. Some items selected from the female sexual function index (FSFI) (5), and other questions added.

The FSFI domain has maximum possible total scores of 36 as in table 1. The FSFI, a 19-item questionnaire, has been developed as a brief, multidimensional selfreport instrument for assessing the key dimensions of sexual function in women. It is psychometrically sound, easy to administer, and has demonstrated the ability to discriminate between clinical and nonclinical populations. The questionnaire described was designed and validated for the assessment of female sexual function and quality of life in clinical trials or epidemiological studies.

In addition, a depression questionnaire was added to exclude the major psychological depressive disorder and its result put with the evaluation questionnaire as one item only as in table 2 .

Table 1: The female sexual function index (FSFI) (Rosen et al., 2000).

\begin{tabular}{|c|c|c|c|c|c|c|}
\hline Domain & Questions & Score Range & Factor & Minimum Score & Maximum Score & Score \\
\hline Desire & 1,2 & $1-5$ & 0.6 & 1.2 & 6.0 & \\
\hline Arousal & $3,4,5,6$ & $0-5$ & 0.3 & 0 & 6.0 & \\
\hline Lubrication & $7,8,9,10$ & $0-5$ & 0.3 & 0 & 6.0 & \\
\hline Orgasm & $11,12,13$ & $0-5$ & 0.4 & 0 & 6.0 & \\
\hline Satisfaction & $14,15,16$ & $0($ or 1$)-5$ & 0.4 & 0.8 & 6.0 & \\
\hline \multirow[t]{2}{*}{ Pain } & $17,18,19$ & $0-5$ & 0.4 & 0 & 6.0 & \\
\hline & & & & 2.0 & 36.0 & \\
\hline
\end{tabular}

Table 2: The total score of PHQ-9 done as following:

\begin{tabular}{lc}
\hline Total score & Depression severity \\
\hline $1-4$ & Minimal depression \\
$5-9$ & Mild depression \\
$10-14$ & Moderate depression \\
$15-19$ & Moderate severe depression \\
$20-27$ & Severe depression \\
\hline
\end{tabular}


The included patients classified into two groups: Group I:26 patients with FSD received 50mg sildenafil on empty stomach at need as the oral dose for 2 months, Group II:26 patients with FSD received placebo tablets at need as an oral dose for 2 months.

Statistical Analysis: The collected data were computerized and statistically analyzed using SPSS program (Statistical Package for Social Science) version 18.0.SPSS Inc., Chicago, IL, US.

\section{RESULTS}

No significant differences between the studied groups regarding the demographic data (table 3), and pretreatment sexual dysfunction assessment (table 4). There were significant differences between pre and post-treatment of sexual dysfunction assessment regarding group I (table 5). There were no significant differences in posttreatment results between the two studied groups as regard sexual dysfunction except in orgasm ( table 6).

Table 3: Comparison between the studied groups regarding demographic data.

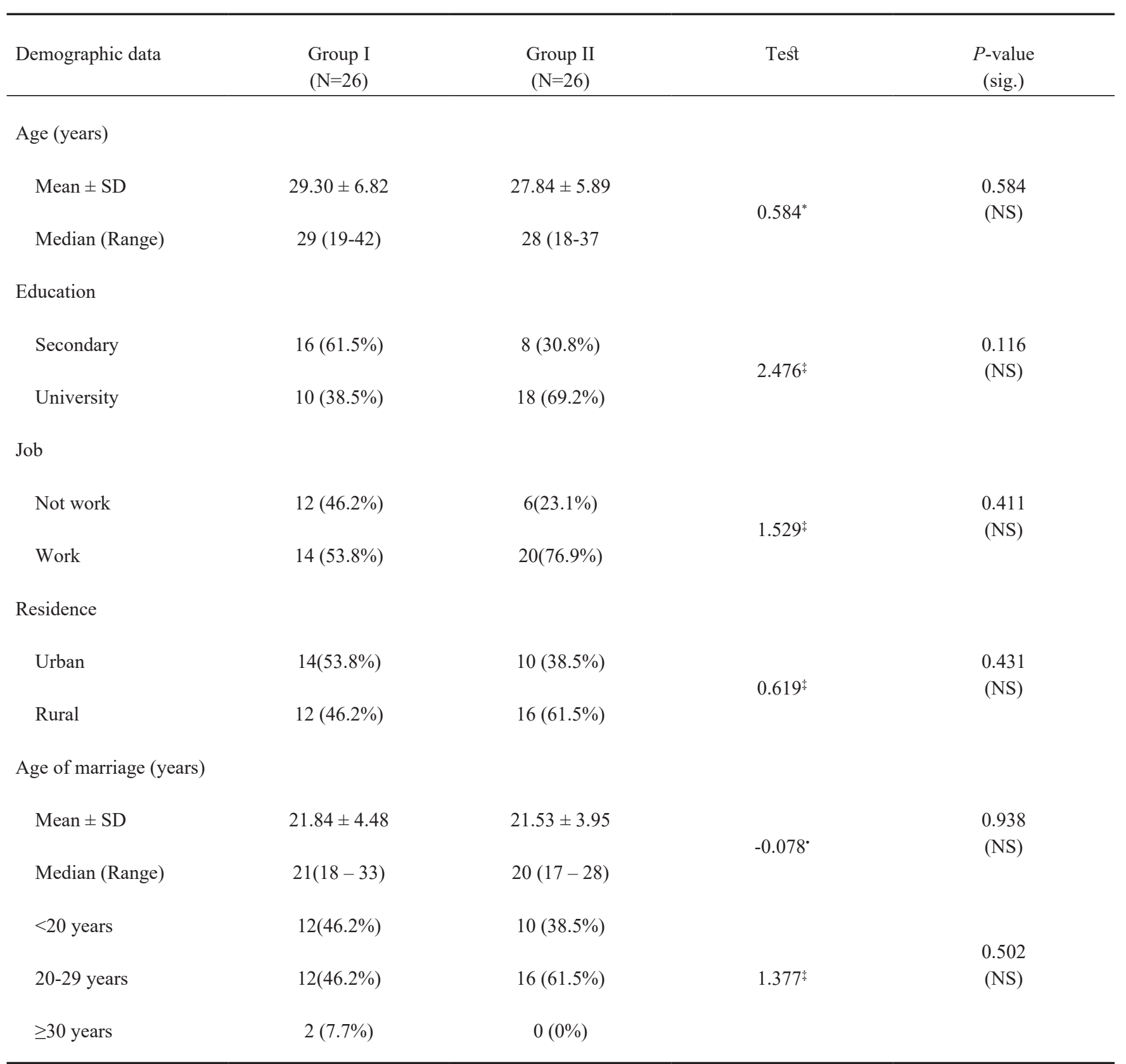

* Independent samples Student's t-test. $\bullet$ Mann Whitney U test. $\$$ Chi-square test. $p<0.05$ is significant. Sig.: significance.

- This table showing that no significant differences between the two studied groups regarding their socioeconomic characteristics. 
Table 4: comparison between the studied groups regarding pretreatment sexual dysfunction assessment

\begin{tabular}{|c|c|c|c|c|}
\hline $\begin{array}{l}\text { Pre-treatment sexual dysfunction } \\
\text { assessment }\end{array}$ & $\begin{array}{l}\text { Group I } \\
(\mathrm{N}=26)\end{array}$ & $\begin{array}{l}\text { Group II } \\
(\mathrm{N}=26)\end{array}$ & Test $^{\ddagger}$ & $\begin{array}{l}P \text {-value } \\
\text { (Sig.) }\end{array}$ \\
\hline \multicolumn{5}{|l|}{ Coital frequency } \\
\hline 2-3/week & $14(53.8 \%)$ & $18(69.2 \%)$ & \multirow{2}{*}{0.650} & \multirow{2}{*}{$\begin{array}{l}0.420 \\
(\mathrm{NS})\end{array}$} \\
\hline $1 /$ week & $12(46.2 \%)$ & $8(30.8 \%)$ & & \\
\hline \multicolumn{5}{|l|}{ Desire } \\
\hline Never & $14(53.8 \%)$ & $6(23.1 \%)$ & \multirow{4}{*}{7.743} & \multirow{4}{*}{$\begin{array}{l}0.052 \\
\text { (NS) }\end{array}$} \\
\hline Monthly & $6(23.1 \%)$ & $8(30.8 \%)$ & & \\
\hline Weekly & $0(0.0 \%)$ & $10(38.5 \%)$ & & \\
\hline Daily & $6(23.1 \%)$ & $2(7.7 \%)$ & & \\
\hline \multicolumn{5}{|l|}{ Lubrication } \\
\hline$<0.5$ trials & $16(61.5 \%)$ & $6(23.1 \%)$ & \multirow{3}{*}{4.545} & \multirow{3}{*}{$\begin{array}{l}0.103 \\
\text { (NS) }\end{array}$} \\
\hline$>0.5$ trials & $6(23.1 \%)$ & $16(61.5 \%)$ & & \\
\hline Mostly & $4(15.4 \%)$ & $4(15.4 \%)$ & & \\
\hline \multicolumn{5}{|l|}{ Maintenance of lubrication } \\
\hline$<0.5$ trials & $16(61.5 \%)$ & $8(30.8 \%)$ & \multirow{3}{*}{3.939} & \multirow{3}{*}{$\begin{array}{l}0.139 \\
\text { (NS) }\end{array}$} \\
\hline$>0.5$ trials & $6(23.1 \%)$ & $16(61.5 \%)$ & & \\
\hline Mostly & $4(15.4 \%)$ & $2(7.7 \%)$ & & \\
\hline \multicolumn{5}{|l|}{ Orgasm } \\
\hline Never & $16(61.5 \%)$ & $10(38.5 \%)$ & \multirow{3}{*}{3.692} & \multirow{3}{*}{$\begin{array}{l}0.158 \\
(\mathrm{NS})\end{array}$} \\
\hline$<0.5$ trials & $10(38.5 \%)$ & $10(38.5 \%)$ & & \\
\hline$>0.5$ trials & $0(0.0 \%)$ & $6(23.1 \%)$ & & \\
\hline \multicolumn{5}{|l|}{ Pain } \\
\hline Absent & $14(53.8 \%)$ & $16(61.5 \%)$ & \multirow{2}{*}{0.158} & \multirow{2}{*}{$\begin{array}{l}0.691 \\
\text { (NS) }\end{array}$} \\
\hline Present & $12(46.2 \%)$ & $10(38.5 \%)$ & & \\
\hline \multicolumn{5}{|l|}{ Satisfaction } \\
\hline Not & $10(38.5 \%)$ & $10(38.5 \%)$ & \multirow{4}{*}{0.311} & \multirow{4}{*}{$\begin{array}{l}0.958 \\
\text { (NS) }\end{array}$} \\
\hline Mild & $6(23.1 \%)$ & $4(15.4 \%)$ & & \\
\hline Moderate & $8(30.8 \%)$ & $10(38.5 \%)$ & & \\
\hline Marked & $2(7.7 \%)$ & $2(7.7 \%)$ & & \\
\hline \multicolumn{5}{|l|}{ Masturbation } \\
\hline Absent & $22(84.6 \%)$ & $20(76.9 \%)$ & \multirow{2}{*}{0.248} & \multirow{2}{*}{$\begin{array}{l}1.000 \\
(\mathrm{NS})\end{array}$} \\
\hline Present & $4(15.4 \%)$ & $6(23.1 \%)$ & & \\
\hline \multicolumn{5}{|l|}{ Depression } \\
\hline Minimal & $22(84.6 \%)$ & $16(61.5 \%)$ & \multirow[b]{2}{*}{1.759} & \multirow[b]{2}{*}{$\begin{array}{l}0.378 \\
(\mathrm{NS})\end{array}$} \\
\hline Mild & $4(15.4 \%)$ & $10(38.5 \%)$ & & \\
\hline
\end{tabular}

$\$$ Chi-square test. $p<0.05$ is significant. Sig.: significance. 
Table 5: Comparison pre-treatment and post-treatment sexual dysfunction assessment.

\begin{tabular}{|c|c|c|c|c|}
\hline \multirow[b]{2}{*}{ Sexual dysfunction assessment } & \multicolumn{2}{|c|}{ Sildenafil group } & \multirow[b]{2}{*}{ Test $^{\ddagger}$} & \multirow{2}{*}{$\begin{array}{c}P \text {-value } \\
\text { (Sig.) }\end{array}$} \\
\hline & $\begin{array}{l}\text { Pre-treatment } \\
\quad(\mathrm{N}=26)\end{array}$ & $\begin{array}{l}\text { Post-treatment } \\
\quad(\mathrm{N}=26)\end{array}$ & & \\
\hline \multicolumn{5}{|l|}{ Coital frequency } \\
\hline 2-3/week & $14(53.8 \%)$ & $22(84.6 \%)$ & \multirow{2}{*}{$2.250^{\ddagger}$} & \multirow{2}{*}{$\begin{array}{c}0.134 \\
\text { (NS) }\end{array}$} \\
\hline $1 /$ week & $12(46.2 \%)$ & $4(15.4 \%)$ & & \\
\hline \multicolumn{5}{|l|}{ Desire } \\
\hline Never & $14(53.8 \%)$ & $2(7.7 \%)$ & \multirow{4}{*}{$9.818^{\cdot}$} & \multirow{4}{*}{$\begin{array}{l}0.007 \\
(\mathrm{~S})\end{array}$} \\
\hline Monthly & $6(23.1 \%)$ & $2(7.7 \%)$ & & \\
\hline Weekly & $0(0 \%)$ & $16(61.5 \%)$ & & \\
\hline Daily & $6(23.1 \%)$ & $6(23.1 \%)$ & & \\
\hline \multicolumn{5}{|l|}{ Lubrication } \\
\hline$<0.5$ trials & $16(61.5 \%)$ & $6(23.1 \%)$ & \multirow{3}{*}{$5.556^{\circ}$} & \multirow{3}{*}{$\begin{array}{c}0.062 \\
\text { (NS) }\end{array}$} \\
\hline$>0.5$ trials & $6(23.1 \%)$ & $12(46.2 \%)$ & & \\
\hline Mostly & $4(15.4 \%)$ & $8(30.8 \%)$ & & \\
\hline \multicolumn{5}{|l|}{ Maintenance of lubrication } \\
\hline$<0.5$ trials & $16(61.5 \%)$ & $8(30.8 \%)$ & \multirow{3}{*}{$4.571^{\circ}$} & \multirow{3}{*}{$\begin{array}{l}0.102 \\
(\mathrm{~S})\end{array}$} \\
\hline$>0.5$ trials & $6(23.1 \%)$ & $10(38.5 \%)$ & & \\
\hline Mostly & $4(15.4 \%)$ & $8(30.8 \%)$ & & \\
\hline \multicolumn{5}{|l|}{ Orgasm } \\
\hline Never & $16(61.5 \%)$ & $2(7.7 \%)$ & \multirow{3}{*}{$8.000^{\circ}$} & \multirow{3}{*}{$\begin{array}{l}0.018 \\
(\mathrm{~S})\end{array}$} \\
\hline$<0.5$ trials & $10(38.5 \%)$ & $22(84.6 \%)$ & & \\
\hline$>0.5$ trials & $0(0 \%)$ & $2(7.7 \%)$ & & \\
\hline \multicolumn{5}{|l|}{ Pain } \\
\hline Absent & $14(53.8 \%)$ & $18(69.2 \%)$ & \multirow{2}{*}{$0.500^{\ddagger}$} & \multirow{2}{*}{$\begin{array}{l}0.480 \\
\text { (NS) }\end{array}$} \\
\hline Present & $12(46.2 \%)$ & $8(30.8 \%)$ & & \\
\hline \multicolumn{5}{|l|}{ Satisfaction } \\
\hline Not & $10(38.5 \%)$ & $2(7.7 \%)$ & \multirow{4}{*}{$10.667^{\circ}$} & \multirow{4}{*}{$\begin{array}{l}0.005 \\
(\mathrm{~S})\end{array}$} \\
\hline Mild & $6(23.1 \%)$ & $0(0 \%)$ & & \\
\hline Moderate & $8(30.8 \%)$ & $22(84.6 \%)$ & & \\
\hline Marked & $2(7.7 \%)$ & $2(7.7 \%)$ & & \\
\hline \multicolumn{5}{|l|}{ Masturbation } \\
\hline Absent & $22(84.6 \%)$ & $22(84.6 \%)$ & \multirow{2}{*}{$1.000^{\ddagger}$} & \multirow{2}{*}{$\begin{array}{c}0.317 \\
(\mathrm{NS})\end{array}$} \\
\hline Present & $4(15.4 \%)$ & $4(15.4 \%)$ & & \\
\hline \multicolumn{5}{|l|}{ Depression } \\
\hline Minimal & $22(84.6 \%)$ & $22(84.6 \%)$ & & 0.317 \\
\hline Mild & $4(15.4 \%)$ & $4(15.4 \%)$ & $1.000^{*}$ & (NS) \\
\hline
\end{tabular}

\$ McNemar's test. $\bullet$ Stuart-Maxwell test. $p<0.05$ is significant. Sig.: significance.

This table shows a significant association between the sildenafil group as regard pre- and post -treatment mostly in desire, orgasm and satisfaction where in pre-treatment in some patient were no desire and after treatment become better with $0.0 \%$ versus $61.5 \%$ respectively. 
Table 6: Comparison between the studied groups regarding post-treatment sexual dysfunction assessment

\begin{tabular}{|c|c|c|c|c|}
\hline $\begin{array}{ll}\text { Post-treatment } & \text { sexual } \\
\text { dysfunction assessment } & \\
\end{array}$ & $\begin{array}{l}\text { Group I } \\
(\mathrm{N}=26)\end{array}$ & $\begin{array}{l}\text { Group II } \\
(\mathrm{N}=26)\end{array}$ & Test $^{\ddagger}$ & $\begin{array}{c}P \text {-value } \\
\text { (Sig.) }\end{array}$ \\
\hline \multicolumn{5}{|l|}{ Coital frequency } \\
\hline 2-3/week & $22(84.6 \%)$ & $22(84.6 \%)$ & \multirow{2}{*}{0.000} & \multirow{2}{*}{$\begin{array}{l}1.000 \\
(\mathrm{NS})\end{array}$} \\
\hline $1 /$ week & $4(15.4 \%)$ & $8(15.4 \%)$ & & \\
\hline \multicolumn{5}{|l|}{ Desire } \\
\hline Never & $2(7.7 \%)$ & $2(7.7 \%)$ & \multirow{4}{*}{1.222} & \multirow{4}{*}{$\begin{array}{l}0.748 \\
\text { (NS) }\end{array}$} \\
\hline Monthly & $2(7.7 \%)$ & $2(7.7 \%)$ & & \\
\hline Weekly & $16(61.5 \%)$ & $20(76.9 \%)$ & & \\
\hline Daily & $6(23.1 \%)$ & $2(7.7 \%)$ & & \\
\hline \multicolumn{5}{|l|}{ Lubrication } \\
\hline$<0.5$ trials & $6(23.1 \%)$ & $2(7.7 \%)$ & \multirow{3}{*}{1.286} & \multirow{3}{*}{$\begin{array}{l}0.526 \\
(\mathrm{NS})\end{array}$} \\
\hline$>0.5$ trials & $12(46.2 \%)$ & $16(61.5 \%)$ & & \\
\hline Mostly & $8(30.8 \%)$ & $8(30.8 \%)$ & & \\
\hline \multicolumn{5}{|l|}{ Maintenance of lubrication } \\
\hline$<0.5$ trials & $16(61.5 \%)$ & $4(15.4 \%)$ & \multirow{3}{*}{1.502} & \multirow{3}{*}{$\begin{array}{l}0.472 \\
\text { (NS) }\end{array}$} \\
\hline$>0.5$ trials & $6(23.1 \%)$ & $16(61.5 \%)$ & & \\
\hline Mostly & $4(15.4 \%)$ & $6(23.1 \%)$ & & \\
\hline \multicolumn{5}{|l|}{ Orgasm } \\
\hline Never & $2(7.7 \%)$ & $6(23.1 \%)$ & \multirow{3}{*}{7.838} & \multirow{3}{*}{$\begin{array}{l}0.020 \\
(\mathrm{~S})\end{array}$} \\
\hline$<0.5$ trials & $22(84.6 \%)$ & $8(30.8 \%)$ & & \\
\hline$>0.5$ trials & $2(7.7 \%)$ & $12(46.2 \%)$ & & \\
\hline \multicolumn{5}{|l|}{ Pain } \\
\hline Absent & $18(69.2 \%)$ & $24(92.3 \%)$ & \multirow{2}{*}{2.229} & \multirow{2}{*}{$\begin{array}{l}0.322 \\
\text { (NS) }\end{array}$} \\
\hline Present & $8(30.8 \%)$ & $2(7.7 \%)$ & & \\
\hline \multicolumn{5}{|l|}{ Satisfaction } \\
\hline Not & $2(7.7 \%)$ & $6(23.1 \%)$ & \multirow{4}{*}{1.807} & \multirow{4}{*}{$\begin{array}{l}0.405 \\
\text { (NS) }\end{array}$} \\
\hline Mild & $0(0 \%)$ & $0(0 \%)$ & & \\
\hline Moderate & $22(84.6 \%)$ & $16(61.5 \%)$ & & \\
\hline Marked & $2(7.7 \%)$ & $4(15.4 \%)$ & & \\
\hline \multicolumn{5}{|l|}{ Masturbation } \\
\hline Absent & $22(84.6 \%)$ & $20(76.9 \%)$ & \multirow{2}{*}{0.248} & \multirow{2}{*}{$\begin{array}{l}1.000 \\
\text { (NS) }\end{array}$} \\
\hline Present & $4(15.4 \%)$ & $6(23.1 \%)$ & & \\
\hline \multicolumn{5}{|l|}{ Depression } \\
\hline Minimal & $22(84.6 \%)$ & $16(61.5 \%)$ & \multirow{2}{*}{1.759} & \multirow{2}{*}{$\begin{array}{l}0.378 \\
(\mathrm{NS})\end{array}$} \\
\hline Mild & $4(15.4 \%)$ & $10(38.5 \%)$ & & \\
\hline
\end{tabular}

† Chi-square test. $p<0.05$ is significant. Sig.: significance.

The table showing there is a significant association between orgasm and type of treatment where $84.6 \%$ of sildenafil group had frequency $<0.5$ time versus $30.8 \%$ of placebo group. 


\section{DISCUSSION}

Sexual dysfunction is defined as a disturbance in the sexual response cycle ${ }^{[6]}$. The family as the center and core of all human societies is based on the sexual instinct ${ }^{[7]}$. Female sexual problems have not received much attention as men sexual problems especially in Arab countries ${ }^{[8]}$.

The current study was conducted to evaluate the effect of sildenafil citrate on female sexual dysfunction. The included sample was composed of 52 women complain of sexual dysfunction and divided into two equal groups. Twenty-six women in-group I who received sildenafil citrate $50 \mathrm{mg}$ for 2 months, and 26 women in-group II who received a placebo. All patients were evaluated with a detailed medical and sexual history, including FSFI and depression questionnaire.

Overall, most of the patients who received sildenafil were living in urban areas (53\%). All patients of this study were educated variant between secondary and university levels those have more accurate results, due to an association between formal education and the desire and ability to obtain extra information through the media, which are more accessible in cities than in rural areas. Conversely, being a member of the conservative family and living in an area where the population is in poor health were associated with a lack of access to information and a lower level of awareness. As El-Gelany and Moussa ${ }^{[9]}$ identified a high level of studies at the university, exposure to the media, and living in modernized cities were the main contributing factors to a high awareness of reproductive health issues. The most common age for marriage was between 20-29 years 12 from 26 in-group I and 16 from 26 in-group II.

There was no variety among studied groups regarding the pre-treatment sexual function assessment with its all items. As for the unprovoked desire to have sex, no statistically significant difference between the two groups was found. This means that the demographic data has no particular effect on female sexuality and both groups were at the same baseline pretreatment. This is similar to the conclusion of Spector et al. ${ }^{[10]}$ who stated that the sexual desire, which is an aspect of a person's sexuality, varies significantly from one person to another, and varies depending on the surrounding circumstances at a particular time.

Comparing the effect of residence on female sexuality, the study showed higher figures in urban areas regarding coital frequency, ability to reach orgasm, overall satisfaction with sexual life, the practice of premarital masturbation and knowledge about it. However, the frequency of experiencing unprovoked desire seemed to be unaffected by residence. These results mean that the sexual function of women resident in cities is better than those living in villages. This may be due to a better level of education, sexual knowledge or socioeconomic factors.

Christensen et al. ${ }^{[11]}$ showed in their study that men and women who had trouble in paying their bills were twice as likely to report sexual dysfunctions compared with peers without such economic problems. In women, there was also a statistically significant trend of increasing sexual dysfunction prevalence with decreasing household income. As regard masturbation practice before marriage, which was more common among participants living in the city.

In our study, $53.85 \%$ of participants living in town and $46.15 \%$ in the village about $80.76 \%$ of them stated that they did not know what masturbation is; this may be related to our customs and traditions, which make some women, ignore sexual knowledge or our culture, which discourage sexual education.

Our study reveals no significant differences between the two studied groups regarding the desire that was never in $(53.8 \%)$ vs $(23.1 \%)$ While monthly in $(23.1 \%)$ VS (30.8\%) but weekly $(0.0 \%)$ VS $(38.5 \%)$ and daily (23.1\%) VS (7.7\%) in sildenafil and placebo respectively. Regarding orgasm, our study did not show any significant differences between the two groups as it was never in $(61.5 \%)$ VS $(38.5 \%)$, less than half times in $(38.5 \%)$ VS (3805\%), and more than half times in $(0.0 \%)$ VS $(23.1 \%)$ in sildenafil and placebo simultaneous.

On the opposite side, the study of Abdallah et al. ${ }^{[12]}$ which carried in Egypt found that Sexual satisfaction seemed to be associated with residence as $(26.4 \%)$ and (39.1\%) of participants living in town were very and moderately sexually satisfied compared to $(18.2 \%)$ and $(20.5 \%)$ of women living in villages who were very and moderately sexually satisfied. Regarding masturbation $(17.3 \%)$ of town, residents practiced it before marriage versus $(11.4 \%)$ of those living in a village and $(59 \%)$ of participants living in town and $(54.5 \%)$ of participants living in rural areas stated that they did not know what masturbation is.

On the same side, the study carried by Omidi et al. ${ }^{[13]}$ in Iran that comparing the two groups in terms of primary mean scores of sexual function, sexual satisfaction, and marital satisfaction showed similarities in terms of factors and prevalence of disorders at the beginning of the study.

In the present study, there is an improvement in sexual dysfunction, where the improvement occurred in desire, and maintenance of lubrication, orgasm, and satisfaction. Regarding the desire, the most different result appears in the patients with no desire weekly pretreatment to improve from $(0.0 \%)$ VS $(61.5 \%)$ post-treatment, the orgasm differences between pre and post in women who achieved 
orgasm less than half the time $(38.5 \%)$ VS $(84.6 \%)$ in pre and post-treatment respectively. [Satisfaction changes that make significant differences between pre and posttreatment appears in women that were moderately satisfied from $(30.8 \%)$ VS (84.6\%)].

Indeed these results were opposite the study of Das Gupta et $a l^{[14]}$ in the study of 19 women completed the 2 arms of the double-blind phase and 12 completed the optional open-label extension phase. Statistically significant improvement following sildenafil was only reported in the lubrication domain of sexual function during the double-blind phase. There was no overall change in the quality of life after sildenafil. There was a significant correlation between the latency of tibial and pudendal evoked potentials.

Where these results were also oppose the results of the study of Berman et al. ${ }^{[15]}$ as efficacy was shown on only one sexual function measure and only in a small subsample of women who had no associated hypoactive sexual desire disorder (HSDD) and had sufficient estradiol and free testosterone concentration or were receiving estrogen and/or androgen replacement therapy. Proposed reasons for the unconvincing efficacy of sildenafil in women have included failure to adequately characterize the study populations, differences in the physiologic response to sildenafil in men and women, and the mechanism of action of the drug needing to be central and not peripheral. It is also possible that a lack of concordance between physiological and subjective aspects of women's sexual experiences need to be further investigated Chivers et al. ${ }^{[16]}$.

This study revealed no significant association between the two groups in comparison of post-treatment regarding sexual dysfunction assessment except in orgasm less than half times, which become (84.6\%) VS (30.8\%) in sildenafil group and placebo group, respectively.

These results supported by the study carried by Leddy et al..$^{[17]}$ as thirteen of $19(68 \%)$ subjects achieved $\mathrm{a} \geq 50 \%$ increase in clitoral engorgement from baseline when administered sildenafil or placebo 30 minutes after dose administration. At 60 minutes after administration, $17 / 19$ (89\%) subjects receiving sildenafil and $16 / 19(84 \%)$ subjects receiving placebo had responded ( $P$-value 0.3173$)$.

Also, Chiver et al. ${ }^{[16]}$ studies using self-reported measures of sexual functioning showed mixed results whereas studies examining the physiological effects of PDE5 on genital vasocongestion consistently report significant effects on genital sexual response.

The improvement in FSFI in group1 may be related to increase in androgen level as there is a positive correlation between sildenafil intake and increase testosterone blood level ${ }^{[18]}$, also it increases the pelvic blood supply which may give more improvement in lubrication and decrease pain during the sexual act and decrease overall sexual satisfaction.

However, Lo Monte et al. ${ }^{[19]}$ stated that sildenafil citrate only acts on the physical phenomena of arousal and does not completely respond to the complexity of female sexual arousal disorders (FSADs). In fact, encouraging results were achieved in specific groups of patients affected by secondary FSADs (e.g., diabetes mellitus, multiple sclerosis, chronic antidepressant users) in which the genital arousal disorder is clearly con $\neg$ nected with a neurological or vascular injury ${ }^{[3]}$

Also, Kaplan et al. ${ }^{[20]}$, reported only lubrication changes in vaginal and clitoral sensitivity in patients treated with sildenafil. When examining the effects of sildenafil on female sexual dysfunction, it was found that sildenafil may increase congestion of the vagina, but it has no effect on excitement. This difference in results can be attributed to the manner and extent of drug administration, assessment of sexual status, and cultural status of the subjects in the study. Moreover, in most studies, the sample size has been very small, which makes their validity questionable.

\section{CONCLUSION}

Finally, we can conclude that sildenafil is effective in the treatment of female sexual dysfunction. As it improves orgasm.

\section{CONFLICT OF INTEREST}

There are no conflicts of interest.

\section{REFERENCES}

1. Desilva P. Sexual dysfunction in S.J.E Lindsay and G.E.Powell , The hand book of lineal and adult psychology . London and New York rout ledge 1995; (2): 199-288.

2. Jaafapour M ,Khani A, Khajavikhan J , Suhrabi Z. Female sexual dysfunction, prevalence and risk factor and diagnosis. Journal of clinical and diagnostic research 2013; 7 (12): 2877-2880.

3. Caruso S, Rugolo S, Angello C, Intelisano G, Di Mari L, Cianci A. Sildenafil improve sexual functioning in premenopausal women with type 1 diabetes who are affected by sexual arousal disorder. Fertility and Sterility. 2006; 85(5): 1496-1501.

4. Berman JR, Berman LA, Toler SM, Gill J, Haughie S. Safty and efficacy of sildenafil citrate for the treatment of female sexual arousal disorder.Journal of Urology.2003; 170(6): 2333-2338. 
5. Rosen R, Brown J, Heiman J, Leiblum S, Meston C, Shabsigh R, Ferguson D, D'Agostino R Jr. The Female Sexual Function Index (FSFI): a multidimensional self-report instrument for the assessment of female sexual function. J Sex Marital Ther. 2000; 26(2): 191-208

6. American Psychiatric Association(1994): DSMIV. Diagnostic and Statistical Manual of Mental Disorders, 4th ed. Washington DC: American Psychiatric Association.

7. Amirkhan Z, Jangholi E, Ramezi P, Shafiei M, Saberi M, S, et al., (2014): Prevalence Survey of Sexual Dysfunction among Women in the Reproductive Age. Galen Medical Journal; 3: (1).

8. Elnashar AM, El-Dien Ibrahim M, El-Desoky MM, Ali OM, El-Sayd Mohamed Hassan M. Female sexual dysfunction in Lower Egypt. BJOG. 2007;114(2):201-6.

9. El Gelany S and Moussa O (2013): Reproductive health awareness among educated young women in Egypt. Int J GynecolObestet; 120: 23-26.

10. Spector IP, Carey MP and Steinberg L (1996): The sexual desire inventory. Development factor, structure, and evidence of reliability. J Sex Marital Ther; 22(3): 175-90.

11. Christensen B S, Grønbæk M, Osler M, Pedersen B V,Graugaard C, and Frisch M (2011): Sexual dysfunction and difficulties in Denemark. Prevelance and associated socio-demographic factors. Arch sex behave; 40(1) 121-132.

12. Abdallah I Y, and AbdelrahmanSh (2014): female sexual dysfunction in relation to the age of marriage. thesis submitted for fulfillment of master degree in dermatology and Andrology in Banha city, Egypt, Banha university.
13. Omidi A, Ahmedvand A, Najarzadan MR, and Mehrzad F (2016):Compairing the effect of treatment with sildenafil and cognitive-behavioral therapy on treatment of sexual dysfunctioninwomen :arandomized controlled clinical trials. Electronic Phsicians; 8(5): 2315-2324.

14. Das Gupta R, Wiseman OJ, Kanabar G, Fowler CJ, Mikol D. Efficacy of sildenafil in the treatment of female sexual dysfunction due to multiple sclerosis. J Urol 2004; 171(3): 1189-1193.

15. Berman JR, Berman LA, Toler SM, et al.,(2003). Safty and efficacy of sildenafil citrate for the treatment of female sexual arousal disorder. Journal of Urology 170(6);1,2333-2338.

16. ChiversMI, and Rosen RC (2010): Phosphodiesterase type 5 and female sexual response. Faulty protocols or paradigins? J Sex Med; 7(2): 858-872.

17. Leddy LS, Yang CC, Stuckey BG, Sudworth M, Haughie S, Sultana S, Maravilla KR. Influence of sildenafil on genital engorgement in women with female sexual arousal disorder. J Sex Med 2012; 9(10)2693-7.

18. Spitzer M, Bhasin S, Travison TG, Davda MN, Stroh H, Basaria S. Sildenafil increases serum testosterone levels by a direct action on the testes. Andrology 2013;1:913-918.

19. Lo Monte G, Graziano A, Piva I, Marci R. Women taking the blue pill (sildenafil citrate) such big deal. Drug Design, Development and Therapy. Dove Press 2014; 8: 2251-2254.

20. Kaplan SA, Reis RB, Kohn IJ, Ikeguchi EF, Laor E, Te AE, Martins AC. Safety and efficacy of sildenafil in postmenopausal women with female sexual dysfunction. Urology 1999; (53):481-486. 